\title{
SP(RACHE). EL BACILO LINGÜÍSTICO DE LA VENGANZA Y LA IDEA DE ETERNO RETORNO EN NIETZSCHE
}

\author{
$S p$ (rache). The linguistic bacillus of revenge and the idea \\ of eternal return in Nietzsche
}

\author{
Marco Carassai
}

Università degli Studi di Roma «La Sapienza»

\begin{abstract}
RESUMEN: La intención teórica que pretende este estudio es la de exponer la idea del eterno retorno sobre el terreno filosófico del lenguaje. Se puede captar en la reflexión de Nietzsche, más allá del análisis psicológico, un estatus lingüístico-gramatical de la venganza. La omnipresencia de este instinto es tan radical que se entrelaza con la omnipresencia de la metafísica del lenguaje. La venganza empuja a la búsqueda del culpable, del autor, de la causa, del sujeto, y está conectada con el gesto fundador de la metafísica en general. Pero esta búsqueda vengativa de un autor está enraizada ante todo en funciones gramaticales, en la estructura sintáctica del discurso, que declina cada evento en agente y actividad. La liberación de la venganza, que promete Zaratustra con el eterno retorno, puede ser interpretada como un intento paradójico de redención de la última «sombra de Dios», de la fe en la gramática.

Palabras clave: lenguaje - venganza - gramática - eterno retorno
\end{abstract}

ABSTRACT: The purpose of this paper is to present the Nietzschean concepts of revenge and eternal return on philosophical grounds of language. One can grasp in the reflection of Nietzsche, beyond psychological analysis, a linguistic-grammatical meaning of «revenge». The pervasiveness of this instinct is so radical that it is intertwined with the pervasiveness of the metaphysics of language. The revenge drives in search of the culprit, of the author, of the cause, of the subject, and it is linked with the founding gesture of metaphysics in general. But this vengeful research of an author is rooted first and foremost in grammatical functions, in the predicative structure of the speech, which declines each event according to agent and activities. The deliverance from revenge, that Zarathustra promises with the eternal return, can be interpreted as a paradoxical attempt to get free from the last shadow of God, the faith in grammar.

Keywords: Language - Revenge - Grammar — Eternal Return

En su camino arqueológico del saber, titulado Las palabras y las cosas, Foucault constata que el lenguaje solo aparece de manera neta en el campo del pensamiento hacia finales del siglo XIX. Aun prescindiendo de esta singular caracterización de la modernidad, sigue siendo significativo que, según Foucault, el primero en haber acercado la «tarea filosófica a una reflexión radical sobre el lenguaje» ha sido Nietzsche $^{1}$. Con más precisión —si por filología se entiende el «análisis de lo que se dice en lo profundo», es decir, «la forma moderna de la crítica»— el Nietzsche

1. M. Foucault, Las palabras y las cosas, Madrid: Siglo XXI, 1997, p. 297. 
«filólogo»². En torno a esta figura se habría radicalizado una trasformación epistemológica - una auténtica cesura del saber-que pone en el centro el lenguaje. La filología ya no desarrolla un movimiento desde el lenguaje a la realidad denotada. Más bien, la búsqueda filológica se mueve desde la lengua a los pliegues escondidos que contiene y produce. Un movimiento de excavación interna en el lenguaje, que no obstante extiende su superficie, amplificando su dominio hacia espacios inéditos con consecuencias decisivas para la filosofía. Nietzsche abriría para nosotros un espacio filosófico-filológico, en el que el lenguaje mismo irrumpe en su complejidad enigmática, desencadenando una constelación de cuestiones en la que quizá el pensamiento, aún hoy, sigue habitando.

Filósofo contra los filólogos y filólogo contra los filósofos, Nietzsche ya en 1869 cierra la conferencia sobre Homero y la filología clásica con una inquietante «confesión de fe», que se conservará intacta durante toda su trayectoria: philosophia facta est quae filologia fuit (OC II «Homero y la filología clásica», 231). En el mismo periodo anota en sus apuntes: «El lenguaje es lo más cotidiano: hace falta un filósofo para ocuparse de él» ${ }^{3}$. La tesis que recorre el presente estudio es que la obra de Nietzsche puede ser considerada como una enorme empresa de carácter filológico, que ensaya una genealogía y una transvaloración radical del logos metafísico en el terreno privilegiado de la reflexión sobre el lenguaje ${ }^{4}$. La cuestión del lenguaje en la reflexión de Nietzsche debe ser interpretada además como una praxis teórica inseparable de un proyecto experimental, que recorre por dentro toda la tensión especulativa. Se trata por tanto de repensar la filosofía de Nietzsche como un camino hacia el lenguaje, un camino ante todo hacia sus límites y sus fronteras, a través de los cuales emergen los márgenes mismos. Siguiendo en efecto el hilo

2. Ibid.

3. F. Nietzsche, Werke, historisch-kritische Gesamtausgabe, C. H. Beck'sche Verlagsbuchhandlung, München, 1933-1940, 5 vols., vol. V, p. 286.

4. Sobre Nietzsche y el lenguaje, cf. Cf. K. Schlechta, «Nietzsche über den Glauben an die Grammatik»: Nietzsche-Studien 1 (1972), 353-358; J. Simon, «Grammatik und Wahrheit über das Verhältnis Nietzsches zur spekulativen Satzgrammatik der metaphysichen Tradition»: NietzscheStudien 1 (1972); P. Lacoue-Labarthe, «Le détour»: Poetique 5 (1971), pp. 53-76; B. Pautrat, Versions du soleil. Figures et système de Nietzsche, Paris: Seuil, 1971; J. M. Rey, L'enjeu des signes: lecture de Nietzsche, Paris: Seuil, 1971; S. Kofman, Nietzsche et la métaphore, Paris: Payot, 1972; M. Haar, «Nietzsche et la maladie du langage»: Revue philosophique de la France et de l'Éntranger 4 (1978), 403-417; P. de Man, Allegories of Reading. Figural language in Rousseau, Nietzsche, Rilke and Proust, New Haven: Yale UP, 1979; G. Abel, «Nominalismus und Interpretation. Die Überwindung der Metaphysik im Denken Nietzsches», en J. Simon, Nietzsche und die philosophische Tradition, vol. 2, Würzburg: Königshausen-Neumann, 1985, pp. 35-89; J. Simon, «Sprache und Sprachkritik bei Nietzsche», en M. Lutz-Bachmann, Über Friedrich Nietzsche. Einführung in seine Philosophie, Frankfurt a. M.: Knecht, 1985, pp. 63-98; C. Crawford, The beginning of Nietzsche's Theory of Language, Berlin: De Gruyter, 1988; M. Haar, «Nietzsche and Metaphysical Language», en D. B. Allison, The New Nietzsche: Contemporary Styles of Interpretation, London: The Mit Press, 1988; R. Fietz, Medienphilosophie. Musik, Sprache und Schrift bei Friedrich Nietzsche, Würzburg: Königshausen \& Neumann, 1992; E. Behler, «Die Sprachtheorie des frühen Nietzsche», en T. Borsche, F. Gerratana y A. Venturelli, Centauren Geburten. Wissenschaft, Kunst und Philosophie beim jungen Nietzsche, Berlin: de Gruyter, 1994, pp. 99-111 ; C. Kalb, Desintegration. Studien zu Friedrich Nietzsches Leib- und Sprachphilosophie, Frankfurt am Main: Suhrkamp, 2000, pp. 5-36; J. Constancio y M. J. Branco, Nietzsche on Instinct and Language, Berlin/Boston: De Gruyter, 2011; J. Constancio y M. J. Branco, As The Spider Spins. Essays on Nietzsche Critique and Use of Language, Berlin/Boston: de Gruyter, 2012. 
conductor del lenguaje, se puede captar un significado filosófico-lingüístico inédito en el interior de la idea del eterno retorno.

Nietzsche muestra en Así habló Zaratustra que la idea de eterno retorno representa una temporalidad diferente, que pretende liberar del instinto de venganza en el que el hombre está preso. Nuestra hipótesis es que se puede hacer emerger en la obra de Nietzsche, más allá del análisis psicológico, un estatus lingüístico-gramatical del instinto de venganza ${ }^{5}$. La prevalencia de este instinto, por la que, según Zaratustra, el hombre debe ponerse y superarse a sí mismo, puede ser tan radical como para confundirse con la prevalencia de la metafísica del lenguaje. Si el eterno retorno es descrito como liberación de la venganza, esta idea sería el último ensayo paradójico de liberación con respecto a la sombra de Dios, a la fe en la gramática; justo esta hipótesis abre espacios hermenéuticos inéditos para la idea de eterno retorno.

Para comprender el inquietante enraizamiento del instinto de venganza en la metafísica del lenguaje, es útil dirigirse a la crítica lingüístico-gramatical de Nietzsche, asumiendo en particular el análisis del concepto de 'causa' como hilo conductor. La crítica del esquema «causa-efecto» ${ }^{6}$ emerge ya en 1872 , justamente en el núcleo en la interconexión entre el elemento lógico y el retórico-lingüístico de la experiencia: «tiempo, espacio y causalidad no son más que metáforas del conocimiento, con las que nosotros interpretamos las cosas» (FP I 367: 19[210]). En particular, podemos leer que el sentimiento de causalidad, por el que «Toda afección provoca una acción, toda acción una afección — este sentimiento, el más generalizado, es ya una metáfora» (ibid.). Más adelante, Nietzsche extiende el análisis de la 'seducción' de este esquema lógico y epistemológico tan universal, desde el ámbito retórico, al gramatical, en realidad dos ámbitos secretamente conectados.

La desconstrucción de la relación causal es particularmente significativa porque encarna el esquema privilegiado por la crítica de Nietzsche a la imagen metafísica del tiempo, la imagen lineal. El tiempo lineal, que unifica causa y efecto, no es otra cosa más que el resultado de un burdo proceso de asimilación, que construye una base para cada proceso de 'identificación', necesario para mantener las identidades perceptivas o ideales, el mundo de los casos idénticos. Las construcciones del 'caso idéntico', en que trabaja el lenguaje, necesitan pensar el tiempo como una sucesión lineal. Emerge aquí la complicidad decisiva entre la estructura del lenguaje y cierta imagen del tiempo, ordenadas por una lógica endurecida de asimilación. Esta complicidad es la base a partir de la cual Nietzsche muestra en qué sentido la imagen de un tiempo inflexible, lineal y funcional está conectada de manera radical con la identidad del sujeto consigo mismo, efectos ambos de la misma ficción lingüísticogramatical. La imagen de un tiempo inflexible está estrechamente ligada a la imagen de la unidad absoluta del sujeto. El sujeto y el tiempo lineal se muestran conectados por la misma inflexibilidad ${ }^{7}$ inscrita en la articulación del lenguaje.

5. El único estudio que propone esta hipótesis es el de S. Zanetti, «Nietzsches Verhör der Gerechten. Bemerkungen zur Kunst und zur Sprache der Sprache in einigen Texten Nietzsches»: Nietzsche-Forschung, 7 (2000), 307-320. De todos modos, Zanetti no extrae las consecuencias hermenéuticas acerca de la idea de eterno retorno.

6. Cf. P. Mauch, «Nietzsches Reihenfogenargument. Friedrich Nietzsches Kritik der Kausalität als Einwand gegen die Transzendentalphilosophie»: Nietzsche-Forschung, 16 (2009), 161-174.

7. Cf. L. A. Manfreda, Tempo e redenzione. Linguaggio etico e forme dell'esperienza da Nietzsche a Simone Weil, Milano: Jaca Book, 2001, p. 42. 
La pareja 'causa-efecto', por lo demás, es completamente especular a la ficción de la identidad del 'yo', entendido como 'sujeto de la causalidad'. En este sentido, la destrucción de las categorías de causa-efecto se convierte en nudo problemático de una importante operación teórica de Nietzsche, que conecta la crítica lingüístico-gramatical y la crítica del tiempo lineal. En una larga nota sobre el concepto de causa, Nietzsche escribe:

No tenemos ninguna experiencia en absoluto sobre una causa: comprobado psicológicamente, el concepto entero nos llega del convencimiento subjetivo de que nosotros somos causa, es decir, que el brazo se mueve... Pero eso es un error: nosotros distinguimos entre nosotros, los agentes, $\mathrm{y}$ el hacer, $\mathrm{y}$ por todas partes hacemos uso de este esquema, - buscando un agente para cada acontecimiento [...]: ¿qué hemos hecho? Hemos malentendido como causa un sentimiento de fuerza, de tensión, de resistencia, un sentimiento muscular que es ya el comienzo de la acción: o hemos entendido como causa la voluntad de hacer esto y lo otro, porque a esa voluntad le sigue la acción [...] La "causa» no se presenta de ningún modo: de algunos casos en que nos parecía dada y desde los cuales la habíamos proyectado para la comprensión de lo acontecido se ha demostrado el autoengaño. Nuestra "comprensión de un acontecimiento» consistía en que inventamos un sujeto que se convertía en responsable de que algo acontecía y de cómo acontecía. Hemos concentrado en el concepto de «causa» nuestro sentimiento de voluntad, nuestro «sentimiento de libertad», nuestro sentimiento de responsabilidad y nuestra intención de hacer algo: causa efficiens [eficiente] y finalis [final] son, en la concepción fundamental, una única cosa [...]. La cosa, el sujeto, la voluntad, la intención — todo ello es inherente a la concepción de la «causa» (FP IV 543-544, 14[98]).

La puesta en cuestión del concepto de causalidad saca a la luz toda la metafísica tácita anidada en la red lingüístico-gramatical, que legitima una determinada constelación conceptual, en la que «la común filosofía de la gramática» se mueve siempre: la 'cosa' como sustancia, el 'sujeto' como autor, la 'intención' y la 'voluntad' como unidades preordenadas e independientes de toda conexión con la contingencia. El fragmento continúa de manera significativa: «La interpretación de la causalidad es una ilusión El movimiento es una palabra, el movimiento no es una causa - una 'cosa' es la suma de sus efectos, unidos sintéticamente por un concepto, una imagen No hay causas ni efectos. Lingüísticamente, de eso no sabemos librarnos» (ibid.).

La causalidad no es pues solo una interpretación de los fenómenos, sino que se enraíza en la articulación del mundo custodiada en el lenguaje. El sujeto de la causalidad se origina a partir de la ficción lingüística, que duplica el agente y la actividad, según las funciones gramaticales del sujeto y el predicado. «La creencia en la causalidad se remonta a la creencia de que soy yo el que actúa, a la separación del 'alma' de su actividad. O sea, iuna antiquísima superstición!» (FP IV 49: 1[38]); tan antigua como el lenguaje.

«Causa» y «efecto»: revisado psicológicamente, es la creencia que se expresa en el verbum, activum, passivum, hacer y padecer. Es decir: la división del acontecer en un hacer y un padecer, la suposición de un agente es previa. Detrás está la creencia en el agente: como si, una vez sustraída toda acción del «agente», este aún permanecie$r a$. Lo que aquí siempre ejerce de guía es la «representación del yo». «Todo acontecer es interpretado como hacer: con la mitología de un ser correspondiente al 'yo'» (FP IV 188: 7[1]). 
Nietzsche describe varias veces esta dinámica de desdoblamiento, inscrita en la gramática: un contragolpe de la lengua, que conjuga todo evento según el verbo, que necesita a su vez un sujeto, un autor. Se trata de una enorme falsificación que pone el 'sujeto' dentro de una determinada dimensión temporal de tipo lineal, que garantiza su subsistencia y mide sus posibles modificaciones, el horizonte de la 'comparación' y la 'identificación' - por tanto, que es especular respecto al Subjektgefühl. Reducido a un dispositivo que permite la reconducción de toda modificación a un sujeto, de todo efecto a una causa, el tiempo lineal está subordinado al régimen gramatical del lenguaje.

¿Pero qué significa para Nietzsche «instinto de venganza»? «Observo algo y busco una razón de ello: esto quiere decir originariamente: busco en ello una intención, y sobre todo a alguien que tenga la intención, un sujeto, un agente» (FP IV 101; 2[83]): esta búsqueda del agente, que también busca un sujeto, del culpable, de la causa, del principio, de la esencia, es descrita por Nietzsche como instinto de venganza.

En todas partes en que se han buscado responsabilidades, el que las ha buscado ha sido el instinto de venganza. Durante milenios este instinto de venganza ha dominado de tal modo a la humanidad que con su distintivo ha marcado a la metafísica entera, a la psicología, a la concepción de la historia y, sobre todo, a la moral. Por lejos que el ser humano haya llegado, aunque solo sea con su pensamiento, hasta allí ha inoculado en las cosas el bacilo de la venganza. Con lo cual a Dios mismo lo ha puesto enfermo, el ser humano ha privado a la existencia en general de su inocencia: con el siguiente procedimiento, remitiendo todo ser de tal y tal manera a la voluntad, a intenciones, a actos de responsabilidad. La teoría entera de la voluntad, esta falsificación que es la más funesta de la psicología que ha habido hasta ahora, se inventó esencialmente para fines de venganza. Fue la utilidad social del castigo la que a este concepto le garantizo su dignidad, su poder, su verdad (FP IV 636: 15[30]).

El instinto de venganza parece describir una temporalidad del resentimiento que escande, de manera inquietante, el ritmo mismo de todo actuar y de todo pensar del hombre ${ }^{8}$. Heidegger ha sacado a la luz de manera decisiva la centralidad de la reflexión sobre el instinto de venganza en el pensamiento de Nietzsche, mostrando las raíces de este instinto en el concepto metafísico y subjetivista de representación (Vorstellung).

¿Por qué el pensar descansa en el percibir?, ¿̇por qué el percibir se despliega en el representar?, ¿̇por qué el representar es re-presentación??

Nietzsche nos contesta en el tercer fragmento de la segunda parte de Así habló Zaratustra. Lo titula: »De la salvación». Aquí se dice: «El espíritu de venganza: amigos míos, esto fue hasta ahora la mejor reflexión del hombre» ${ }^{10}$.

8. Es interesante, en este sentido, la siguiente definición de 'instinto': «Hablo de instinto cuando un juicio cualquiera [...] se halla asimilado de tal manera que ahora se excita él solo espontáneamente y ya no necesita esperar ningún estímulo. Se desarrolla por sí mismo y en consecuencia también el sentido de su actividad hacia fuera» (FP II XXX, 11[164]).

9. M. Heidegger, «¿Qué quiere decir pensar?», en Conferencias y artículos, trad. de E. Barjau, Barcelona: Serbal, 2001, p. 105.

10. M. Heidegger, «¿¿uién es el Zaratustra de Nietzsche?», en ibid., p. 82. 
El instinto de venganza, observa Heidegger, siempre referido a un sujeto, es ir a la caza (nachstellen) del fundamento. Entonces no es venganza solo la búsqueda de la responsabilidad en sentido estricto, sino toda búsqueda del fundamento, la necesidad misma de un fundamento, el ir a la caza de la identidad del principio, inscrito en todo gesto de fundación metafísica en general ${ }^{11}$.

Frente a un devenir extraño que el hombre no puede incorporar y por el que se siente dominado, el hombre intenta vengarse buscando el fundamento y el responsable, pero en la efectuación de la venganza lo único que hace es reiterar y acrecentar la propia carga, se enreda en el tiempo lineal que lo domina. Pero esta prevalencia del instinto de venganza, que está enraizado como un bacilo en todo pensamiento del hombre, hasta el punto que se confunde con cada gesto fundacional (metafísica, moral, psicología, representación de la historia, etc.), ¿no presenta también en la reflexión de Nietzsche un estatus lingüístico-gramatical?

La venganza no se agota en el análisis psicológico, sino que emerge como traza inscrita en toda representación, en toda relación del hombre con lo que es, ante todo en el hablar. La venganza atraviesa toda representación del hombre, porque se enraíza en la misma estructura predicativa del discurso, es decir, en el lenguaje y sus sistemas de relaciones. La venganza, como un instinto o un espíritu, se enraíza en la predicación, recorriendo por dentro la interpretación gramatical del lenguaje, precisamente a causa del desdoblamiento entre actividad y agente, bajo el que todo evento se ve obligado a amoldarse. En este sentido, es decisivo el fragmento póstumo 2[83] del otoño 1885 — otoño 1886:

Todo lo que sucede se comporta predicativamente respecto de algún sujeto. En todo juicio se encuentra la creencia total, plena, profunda, en el sujeto y el predicado o en la causa y el efecto; y esta última creencia (o sea, la afirmación de que todo efecto es una actividad, de que toda actividad supone un agente) es incluso un caso particular de la primera, de manera tal que queda como creencia fundamental la creencia: hay sujetos (FP IV 101: 2[83])

En distintos pasajes, Nietzsche describe la búsqueda de la causa como una expresión del instinto de venganza: «Todo efecto es seguido por otro efecto - esta creencia en la causalidad se basa en el más fuerte de los instintos, el instinto de venganza» (FP III 100: 4[53]; cf. FP III 282: 12[1]). Pero es la conjugación de todo evento mediante el verbo, como hemos visto, la que requiere la existencia del sujeto y de la causa. La necesidad de la causa, del principio, del autor, del fundamento metafísico en general, está inscrita en las mismas funciones gramaticales del lenguaje. A partir de aquí puede captarse la inquietante y radical complicidad —que Nietzsche llama 'instinto de venganza'- entre lenguaje y metafísica.

La instancia metafísica —incluso teológica - que atraviesa el lenguaje, por la que Dios no es tanto un más allá del saber como un más acá de nuestras frases: «Temo que no vamos a librarnos de Dios porque continuamos creyendo en la gramática» (OC IV CI, «La 'razón' de la filosofía» 5, 633) ${ }^{12}$, consiste en un bacilo

11. Cf. G. Vattimo, Il soggetto e la maschera. Nietzsche e il problema della liberazione, Milano: Bompiani, 1999, p. 261.

12. «Dios es quizá menos un más del saber que un cierto más acá de nuestras frases; y si el hombre occidental es inseparable de él, no es por una propensión invencible a traspasar las fronteras de 
lingüístico de la venganza, en la necesidad de un Autor, de una causa, de un fundamento, custodiada en los esquemas gramaticales de la lengua. Este instinto es tan potente que está enraizado en las mismas funciones lingüísticas que entretejen el discurso, por lo que toda lógica es una teo-lógica, una mitología:

«A toda alteración le corresponde un autor». Pero esta inferencia es ya mitología: $s e$ para lo que produce un efecto y el efectuar. Cuando digo que «el relámpago resplandece», he puesto el resplandecer una vez como actividad, la otra como sujeto: por lo tanto, al acontecer le he puesto un ser que no es idéntico al acontecer, sino que, al contrario, permanece, es y no «deviene». Poner el acontecer como efectuar: y el efecto como ser: ese es el doble error, o interpretación, del que nos hacemos culpables (FP IV 102: $2[84])^{13}$.

La creencia en la causalidad, que se realiza en el nexo lingüístico entre sujeto, predicado y objeto, implica la necesidad de hacer resonar en todo evento, en todo acontecer, un culpable, un autor, un principio. Esta necesidad, cómplice de una instancia moral tácita, observa Mülller, «se convierte en constitutiva por el lenguaje» ${ }^{14}$.

Se podría decir que «en la medida en que el hombre ha hablado, ha introducido en las cosas el bacilo de la venganza». La venganza se enraíza en efecto en «la fe más creída, más antigua, más indiscutible, más honesta, que hay entre los hombres». Incluso tras la muerte de Dios, del Autor y del Fundamento por excelencia, esta fe sigue siendo casi inextirpable, quizá porque es «más inconsciente y estar mejor defendida contra las razones». Así podemos leer:

Admitido; ¿Pero cuál es esta creencia? — iAh, curiosos! Pero ya que me he puesto a plantear enigmas, seré humano y daré enseguida la respuesta y la solución, — no será fácil que alguien se me anticipe.

El hombre es, ante todo, un animal que juzga; pero en el juicio está escondida nuestra creencia más antigua y permanente, en todo juzgar hay, en su base, un tener-porverdadero, una certeza de que algo es de tal manera y no de otra, de que en él el hombre ha «conocido» realmente: ¿̇qué es lo que en todo juicio se cree inconscientemente verdadero? Que tenemos derecho a distinguir entre sujeto y predicado, entre causa y efecto: esta es nuestra creencia más fuerte; en el fondo, la creencia misma en la causa y el efecto, en conditio y conditionatum es ya un caso particular de la creencia primera y general, de nuestra creencia primitiva en el sujeto y el predicado (concretamente en cuanto afirmación de que todo efecto es una actividad y de que todo condicionado supone un condicionante, toda actividad un agente, o sea, un sujeto). ¿No sería esta creencia en el concepto de sujeto y el concepto de predicado < una gran tontería?> (FP IV 148: 4[8]).

la experiencia, sino porque su lenguaje lo fomenta sin cesar en la sombra de sus leyes» (M. Foucault, op. cit., pp. 291-292).

13. Más adelante podemos leer: «¿Qué son los predicados? - Hemos tomado alteraciones en nosotros no como tales sino como un 'en-sí' que nos es ajeno, que nosotros solo 'percibimos': y no las hemos puesto como un acontecer sino como un ser, como una 'propiedad' - y hemos inventado además una identidad a la que son inherentes, ES DECIR, hemos puesto el efecto como lo que produce un efecto y lo que produce un efecto como ente» (FP IV 102).

14. D. Müller, Wider die «Vernunft in der Sprache». Zum Verhältnis von Sprachkritik und Sprachpraxis im Schreiben Nietzsches, Tübingen: Narr, 1995, p. 145. Sobre el nexo entre causa, culpa y sujeto gramatical véase también ibid., pp. 146-150. 
El hombre, precisamente en cuanto hablante, en particular como «animal juzgante», instila en las cosas el bacilo de la venganza. La universalidad del instinto de venganza, que Nietzsche describe, no es más que la prevalencia de la gramática y de su sintaxis, en las que se anida el nihilismo, la privación de inocencia del mundo ${ }^{15}$.

La alineación del tiempo, reflejo de la identidad del sujeto, es el producto de la gramática de la venganza, que requiere un soporte temporal para el ejercicio de sus prácticas: un garante de toda 'investigación' científica ${ }^{16}$, de toda fundación metafísica, de toda punición jurídico-moral. Una vez entendido el dispositivo lingüístico de su cristalización, la venganza se manifiesta en su enraizamiento en el lenguaje, poniéndose como tiempo y gramática 'trascendental' de un dominio irresistible. La genealogía del lenguaje desvela la complicidad entre la subjetividad, la imagen lineal-funcional del tiempo y las funciones gramaticales, que detentan, desde la estructura predicativa misma del discurso, el dispositivo de producción de esta trama metafísica.

Lenguaje, sujeto y tiempo aparecen marcados por la misma inflexibilidad, la inflexibilidad de la venganza, que domina la economía de la representación, de la verdad, de la historia, del sentido, enraizándose como un bacilo en el pensar y el hablar del ser humano. Nos parece que esta es la clase para comprender la importancia radical de la posición de Nietzsche dentro de la tradición occidental, con respecto a la cual debe medirse también el significado filosófico del eterno retorno y del ultra-hombre.

«Pues que el hombre sea redimido de la venganza es, para mí, el puente a la esperanza suprema y a un arcoíris tras largas tempestades» (OC IV Za, Parte II, «De las tarántulas», 130). El eterno retorno está llamado a suspender la linealidad del tiempo, a redimir de la venganza, a interrumpir el orden de la representación, la cual no consigue decir un evento sin conjugarlo, sin domesticarlo, sin cargarlo con el 'así fue' del haber-sido (Gewesen), de la esencia (Wesen), de la causa, del principio. Por esto, la exigencia filosófica custodiada en la idea de eterno retorno afronta la complejidad del enraizamiento gramatical, y por tanto consciencial y temporal, de la venganza.

Se abren así espacios hermenéuticos inéditos para la idea de eterno retorno. Más allá de las interpretaciones tradicionales que evidencian su carácter cosmológicoreligioso (Löwith) ${ }^{17}$, o ético-selectivo (Granier y Deleuze) ${ }^{18}$, ontológico-metafísico

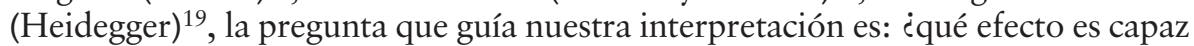
de provocar el eterno retorno en el orden del lenguaje?

Nietzsche mismo, sacando a la luz la tensión experimental que atraviesa la doctrina del eterno retorno, está interesado en indagar la «posible consecuencia de que sea creída (lo lleva todo a la erupción)» (FP III 442, 24[4]). Con esta idea

15. Cf. S. Agacinski, «Grammaire du nihilisme», en Nietzsche Aujourd'hui, Paris: Hermann, 2011, pp. 191-204.

16. «La ciencia tiene que observar cada vez más la sucesión de las cosas en marcha, de manera que los procesos nos resulten factibles» (FP II XXX, 11[255]).

17. K. Löwith, Nietzsches Philosophie der ewigen Wiederkehr des Gleichen, Stuttgart: Kohlhammer, 1956.

18. G. Deleuze, Nietzsche et la philosophie, Paris: PUF, 1962; J. Granier, Le problème de la vérité dans la philosophie de Nietzsche, Paris: Seuil, 1966.

19. M. Heidegger, Nietzsche I, Pfullingen: Neske, 1961, pp. 255-474. 
es con la que culmina su Experimentalphilosophie: «Yo busco y llamo a los hombres a los que puedo comunicar estos pensamientos, que no perecen en ellos» (FP III 660, 29[8]). Nietzsche pone en guardia frente al desafío mortal al que la idea de eterno retorno expone de manera inexorable: «¿Estáis ya preparados? iTendríais que haber pasado en vuestra vida por cierto grado de escepticismo y haberos bañado con voluptuosidad en aguas heladas - si no, no tenéis derecho alguno a este pensamiento!» (FP II 11[339], XXX).

La idea del eterno retorno halla su poder transvalorador exactamente en la medida en que no es domesticable por parte de la inflexibilidad del tiempo y por las estructuras sintáctico-gramaticales que construyen el discurso metafísico (erigido estratégicamente sobre esta inflexibilidad), determinando así su cortocircuito. El tiempo del eterno retorno no puede apoyarse o vincularse al logos, si no es plegándolo, curvándolo, hasta derrumbarlo. Este tiempo diferente emerge en su extremo carácter abisal y desfundante, justamente no pudiendo ser acogido en ese espacio metafísico-gramatical que funciona entre la inflexibilidad del tiempo y la unidad absoluta del sujeto.

La exigencia filosófica de Nietzsche de pensar el ultrahombre y el eterno retorno puede ser conectada, por tanto, con la complejidad del enraizamiento lingüístico, consciencial y temporal, de la venganza, leyendo en ella el intento paradójico, el último experimento, de superar el resultado más inquietante de su genealogía del lenguaje: en la medida en que el hombre ha pensado, ha introducido en las cosas el bacilo de la venganza. En esta historia de la metafísica, como historia de la venganza, Nietzsche introduce implícitamente la cuestión del nihilismo en su conexión con el lenguaje, una conexión que la idea de eterno retorno está llamada a interrumpir.

En Así habló Zaratustra, el espíritu de venganza está descrito como una tarántula, cuyo veneno es su poder de contagio:

iMira, ahí está la cueva de la tarántula! ¿Quieres verla por ti mismo? Aquí cuelga su telaraña: tócala para que tiemble. [...] Tu triángulo y emblema se asienta, negro, en tu espalda; y también sé lo que se asienta en tu alma. Venganza se asienta en tu alma: allí donde muerdes, se forma una costra negra; itu veneno da vértigos al alma con la venganza! (OC IV, Za Parte II, «De las tarántulas», 130).

El peligro de la tarántula es justamente la mordedura: la mordedura reactiva de la venganza que requiere a su vez una venganza, es decir, que alarga, reiterando su dispositivo de reacción, esa cadena de ofensas que entreteje la historia y convierte cada palabra en un lamento. «Pues que el hombre sea redimido de la venganza es, para mí, el puente a la esperanza suprema y un arcoíris tras largas tempestades» (ibid.). Pero el peligro de la venganza es irresistible: «iAy! iAhora me pica a mí la tarántula, mi vieja enemiga! iDivinamente, con seguridad y belleza, me picó en el dedo! [...] iSí, ella se ha vengado! Y, iay!, iahorra querrá también provocar vértigos a mi alma con su venganza! iPara no sufrir vértigos, amigos míos, atadme fuerte a esta columna!» (ibid., 131-132). La danza de Zaratustra no será una danza por la mordedura de la tarántula: exige no ser provocada por una fuerza reactiva y de no moverse según el ritmo temporal de la venganza.

La idea de un tiempo diferente, que Nietzsche intenta contraponer al tiempo lineal y funcional que funda el logos clásico es por tanto la idea del eterno retor- 
no ${ }^{20}$. «Redimir a los pretéritos y hacer que todo 'fue' se transforme en un 'así lo quise' - isolo esto sería para mí la redención!» (ibid., 157). La exposición de la idea de eterno retorno se anuncia a través de una paradoja, que Nietzsche afronta en el capítulo «De la redención», por la que, si de una parte la voluntad es lo que libera y proporciona alegría, por otra parte, en sí misma está aún aprisionada, cargada del 'así fue'. En efecto, la voluntad es impotente a la hora de romper la voracidad del tiempo: «Que el tiempo no pueda correr hacia atrás es su rabia; ilo que fue! — así se llama la piedra que no puede apartar» (ibid.). Por este motivo se venga contra todo lo que es indiferente a su malhumor, de modo que, en lugar de liberar, inflige sufrimiento hacia todo lo que es capaz de sufrir. El ritmo del tiempo articula el tiempo de la venganza, la 'gran locura' que habita en la voluntad, aprendiendo a convertirse en espíritu: «el espiritu de la venganza: amigos míos, esta ha sido hasta ahora la mejor reflexión de los hombres» (ibid.). El espíritu se acumuló y se trasformó de locura en demencia que predica sus 'cantilenas': la vida como punición, la justicia como ley del tiempo, por la que «este debe devorar a sus hijos», la eternidad de un orden moral que asegura la eternidad de la punición, de modo que «ila propia existencia debe ser eternamente acto y culpa» (ibid., 158). El espíritu de venganza intenta hallar una razón al 'así fue', pero, en el momento mismo en que intenta dominarlo, vuelve a caer sin darse cuenta, una y otra vez, en el mismo encantamiento, alargando así la cadena de las ofensas ${ }^{21}$.

Zaratustra define el 'así fue' como un fragmento, un enigma y una horrenda casualidad, pero él es el 'solucionador de enigmas': «Y este es todo mi pensamiento y mi afán: que yo unifique y lleve unido todo cuanto es fragmento y enigma y horrible azar. iY cómo podría soportar yo ser un hombre si el hombre no fuera también un poeta y un desentrañador de enigmas y el redentor del azar!»; pues en efecto enseña: la voluntad es creadora, de todo 'así fue' ella dice 'pero así lo quise'. Una vez dicho esto, Zaratustra fragmenta su discurso en una multiplicidad exuberante de preguntas:

¿Pero acaso habló ya de ese modo? ¿Y cuándo ocurrirá eso? ¿Se ha soltado ya la voluntad del yugo de su propia estupidez? ¿Se ha vuelto ya la voluntad misma redentora y portadora de alegría? ¿Olvidó el espíritu de la venganza y todo rechinar de dientes? ¿Y quién le enseño la reconciliación con el tiempo y algo más alto que toda reconciliación? [...], pero ¿cómo le ocurrirá eso? ¿Quién le enseñó incluso a querer hacia atrás? (ibid., p. 158).

Llegado a este punto, Zaratustra se interrumpe, vuelve a caer en un inquietante silencio, un contragolpe repentino respecto a su exuberancia: renuncia a enunciar su doctrina. Sus palabras emergen en un margen precario, entre lo inaudito y lo inaudible, asumiendo la potencia de su apertura solo en el límite externo de su inactualidad, en el salto de lo intempestivo. «¿Cómo puede ocurrir esto?»: la exigencia del eterno

20. Cf. F. Rella, Il silenzio e le parole. Il pensiero nel tempo della crisi, Milano: Feltrinelli, 2001; M. Cacciari, Crucialità del tempo. Saggi sulla concezione nietzscheana del tempo, Napoli: Liguori, 2003.

21. Cf. G. Vattimo, «Lo spirito di vendetta e la struttura edipica del tempo», en Il soggetto e la maschera, Milano: Bompiani, 1999, pp. 249-282. Cf. también G. Vattimo, «Nietzsche e il problema della temporalità», en Dialogo con Nietzsche, Milano: Rizzoli, 2000, pp. 11-42. 
retorno parece reunir juntos posibilidad y evento, pero exclusivamente fuera de la gramática que ordena su relación determinada en el interior del discurso metafísico.

El eterno retorno, como destino temporal de una superación de la venganza, no puede derivar de la linealidad, de la calculabilidad, de la consecuencialidad, analizadas como estructuras inflexibles de toda identidad y como propiedad del mundo de los 'casos idénticos'. El eterno retorno entonces se expone como totalmente extraño a las dinámicas del tiempo lineal y a la cadena teórica afín (sujeto, objeto, identidad, sustancia, causa, principio, fin, etc.). En efecto, se pone a sí mismo como instante decisivo - y en el fondo indecidible - que excede toda economía y trabajo que somete el tiempo a la venganza, a la linealización funcional, a la identificación. El instante, en la curvatura del eterno retorno, se ve desarmado de la lógica de causa eficiente y causa final, de origen y fin, indicando el tiempo del retorno en la ausencia de un fundamento y un autor ${ }^{22}$; desobediencia testaruda e irreducible del evento a toda representación, que siempre lo pone en el fundamento, en la identidad, en el autor; irrupción monstruosa de una temporalidad que sacude al ser humano en cuanto animalidad juzgadora. ¿Pero puede la metafísica del lenguaje, es decir, la razón, asumir esta ruptura irreparable del 'caso idéntico', esta autenticación de lo diferente, sin transformarse por ello en algo inaudito e inaudible? Como observa de manera significativa Fink:

El «eterno retorno de lo mismo», la idea más profunda de la filosofía de Nietzsche, se encuentra iluminada por una luz ambigua. Carece, al parecer, de una elaboración y acuñación conceptuales netas; se asemeja más a una oscura profecía, al desvelamiento profético de un misterio, que a una demostración rigurosamente intelectual. Zaratustra es el «maestro del eterno retorno» pero no lo enseña realmente; solo alude a él. Su «visión» del abismo del tiempo la expone como un «enigma». No es, sin embargo, el ambiguo placer por la máscara, por el ocultamiento y el disfraz lo que le lleva a hablar enigmáticamente. Con su concepción del eterno retorno, Nietzsche está al borde de lo que para él es decible, está junto a una frontera de logos, razón y método ${ }^{23}$.

El mismo Nietzsche, después de haber recibido las alabanzas de Gast por el tercer libro del Zaratustra, en una carta del 8 de marzo de 1884 le confiaba a Overbeck su inquietud:

La primera parte de su carta [de Gast] trata de mi Zaratustra, pero la manera en que me habla de él te producirá alarma más que placer. iCielos! Quién sabe qué cometidos tendré que asumir y que energías necesitaré para poder perseverar conmigo mismo. No sé cómo he podido llegar a ello - pero probablemente se me ha ocurrido por primera vez el pensamiento que dividirá a la historia de la humanidad en dos. Este Zaratustra no es más que un preámbulo, un vestíbulo — he tenido que darme ánimos a mí mismo, porque solo recibía el desaliento de todas partes: iel valor para soportar ese pensamiento! Porque aún estoy muy lejos de poder expresarlo y exponerlo (CO IV 442).

22. El eterno retorno representa la crisis de la repetición como esquema-guía de todo régimen de calculabilidad, comparabilidad y asimilación, que gobierna la metafísica del lenguaje como lógica de los casos idénticos. Como observa Deleuze, «la verdadera repetición se dirige a algo singular, de impermutable y diferente, sin identidad. En lugar de intercambiar lo símil y de identificar lo Mismo, ella autentifica lo diferente» (G. Deleuze, Logique du sens, Paris: Minuit, 1969, p. 334).

23. E. Fink, La filosofía de Nietzsche, trad. de A. Sánchez Pascual, Madrid: Alianza, 1969, p. 130. 
Se trata entonces de comprender cómo esta imposibilidad de llevar a la palabra una temporalidad no lineal debe aparecer no solo como el advertimiento de un límite, sino también como una profunda y paradójica exigencia. Por esto, el enano, metáfora del espíritu de gravedad, delante de la puerta del instante, que contrapone las dos vías eternas del pasado y el futuro, simplifica demasiado respondiendo al enigma del eterno retorno, diciendo: «todo lo recto miente [...] la verdad es curva» (Za Parte III, «De la visión y el enigma» 2, OC IV, 167). El eterno retorno es tomado demasiado a la ligera por parte del enano, porque redimensiona el enigma en una simple oposición entre tiempo lineal y tiempo circular. El espíritu de gravedad no se separa del curvarse del tiempo, no experiencia el eterno retorno como el pensamiento más abismal, que hunde de manera inevitable toda gravedad, toda pesadez, toda presencia inmóvil, todo fundamento, incluso toda representación.

En el capítulo «El convaleciente», vuelve a aparecer otra enunciación del eterno retorno, pero no es pronunciada por el «maestro del eterno retorno», sino por sus animales: «Todo va, todo regresa de nuevo: eternamente rueda la rueda del ser. Todo muere, todo vuelve a florecer, el año del ser transcurre eternamente [...] Curvo es el camino de la eternidad» (Za Parte III, «El convaleciente» 2, OC IV, 208). La reacción de Zaratustra a estas palabras no se deja esperar: «iOh, granujas y organillos [...] ¿̇habéis compuesto ya una canción sobre ello con vuestras liras?» (ibid.). También sus animales son demasiado superficiales, y, después de haber intentado otra vez una nueva definición, se dan cuenta de que Zaratustra ha vuelto a caer en un 'gran silencio'.

El mutismo que acompaña el anuncio del retorno es el efecto de un escándalo de la razón y el lenguaje, un síntoma de la irrupción de lo nuevo y de la locura. En Aurora, Nietzsche precisa el papel de la locura en la historia. A pesar de la opresión de la eticidad de las costumbres, «aparecían una y otra vez ideas, pulsiones, juicios de valor nuevos y discrepantes. [...] En casi todos los casos ha sido la locura la que abre el camino a esa idea nueva que viola el interdicto prescrito por el uso y la superstición venerados» (A $\$ 14$, OC III, 469-470) ${ }^{24}$. ¿Pero qué locura podrá romper el hábito más venerable, la superstición más potente? El silencio aparece como la enésima máscara que esconde un saber fatal; el silencio atestigua que la batalla contra la sombra de Dios está destinada al fracaso para el hombre: «dejemos de pensar si no queremos hacerlo bajo la coacción lingüística" solo llegamos hasta la duda de ver aquí un límite como límite» (FP IV 154:5 [22]). Nietzsche con la idea de eterno retorno experimenta la superación de esta frontera, que significa de manera inevitable la superación misma de lo humano. Más allá de su resultado final, este experimento radical atestigua un ensayo grandioso e inaudito del pensamiento de transvaloración del logos y del hombre mismo, entendido como animal jugador.

«El superhombre es lo que amo, él es para mí lo primero y lo único, - y no el hombre» (Za Parte IV, «Del hombre superior», OC IV 251). El Über-mensch en

24. El pasaje persigue de manera significativa: «iAy, dadme, empero, la locura, vosotros, dioses! iLa locura, para que pueda por fin creer en mí! Obsequiadme con delirios y convulsiones, con súbitas luces y sombras, sobresaltadme con un frío helador y un calor ardiente como jamás los haya sentido mortal alguno, envolvedme de estrépitos y fantasmas, haced que llore y gima y que me arrastre como un animal [...] La incertidumbre me consume, he acabado con la ley, y la ley me aterroriza como un cadáver a quien está vivo» (ibid). 
efecto no es una forma mejor del hombre, su realización como hombre acabado y finalmente conciliado, sino que es aquel que está más allá del hombre, más allá de todo lo que ha sido y ha pensado, puesto que, en la medida en que el hombre ha pensado, ha instilado en las cosas el bacilo de la venganza. «La destrucción del lenguaje metafísico», observa de manera significativa Haar, «sería una experimentación empujada hasta la autodestrucción del destructor en cuanto hablante» 25 . La única forma de transvaloración del lenguaje, después del escepticismo más radical, es el 'gran silencio'. O bien, un balbuceo mediante metáforas prohibidas que laceran al sujeto: «iDi lo que tengas que decir y que tu palabra te rompa! ¿Qué importa tu persona!» (FP III 261: 10[35]). El Über-mensch, si es escuchado a fondo, es una forma paradójica de Über-tragung, de trasposición, de metáfora: una afirmación sin origen asignable y que no puede fundarse en ninguna esencia o presencia ya dadas o por venir. No inscribe su gesto a partir de la memoria o del sistema de dominio que la desarrolla, ni, en general, puede conjugarse según las figuras temporales que la metafísica, en el lenguaje, ha constituido y conservado.

[Traducción de Antonio Rovi Ruíz y Marco Parmeggiani Universidad de Málaga]

25. M. Haar, Nietzsche et la métaphysique, Paris: Gallimard, 1993, p. 64. 